marketed; the two seem comparable in their effects. The standard course is $50 \mathrm{mg}$ weekly to a total of $1 \mathrm{~g}$. Possibly the earlier treatment is started the better the result. ${ }^{14}$ McKenzie has advocated lower doses of gold, though the incidence of side effects has proved similar. ${ }^{15}$ Maintenance treatment is useful, but its frequency is still debated. ${ }^{16}$ Rothermich et al stated that four weekly injections were not sufficient and would result in many cases of relapse. ${ }^{17}$ Griffin et al, however, found that improvement was equally well maintained with two or four weekly intervals between 50 $\mathrm{mg}$ maintenance injections, and that toxicity was less with the four weekly intervals. ${ }^{18}$

The mode of action of gold is still not clear; the thiol group may be the important part of the molecule rather than the metal. ${ }^{19}$ The drawback of intramuscular gold is its considerable toxicity: rashes are especially common and up to one third of patients have to be withdrawn early in the course; few maintain their treatment for two years. ${ }^{5}$ Neither the toxicity nor the effectiveness is related to plasma concentrations of the drug. ${ }^{20-22}$ Resistance to treatment has been ascribed to the binding of gold to metallothionein in cells. ${ }^{23}$ Side effects, particularly proteinuria, are associated with the HLA antigen DR3, while to some extent DR7 is protective, but the associations are weak and do not correlate with the severity of adverse reactions. ${ }^{24} 25$

The new oral preparation of gold, Auranofin, has been extensively investigated. It avoids the disadvantage of intramuscular injections, but absorption of gold from Auranofin is variable and relatively poor: most of the dose passes out in the faeces. Total gold concentrations in the blood during treatment are considerably lower than after intramuscular gold. Free gold concentrations, however, may be comparable between treatments. The blood half life of Auranofin varies between 10 and 30 days, and only a small fraction of the dose is excreted by the kidneys. The side effects of Auranofin are less than of intramuscular gold $^{2627}$ - good news for a drug which has been associated with more iatrogenic mortality per prescription than any other antirheumatic preparation. ${ }^{28}$ The main adverse reaction is diarrhoea. ${ }^{26}$ Analysis of several thousand patients treated with oral gold shows that a rash (which occurs in a third of patients having intramuscular gold) is produced half as commonly, alopecia (which is much less frequent) twice as often, taste disorders and stomatitis about equal, and thrombocytopenia half as commonly. Albuminuria occurs with a similar incidence of $4-5 \%$.

Oral gold is an active preparation compared with placebo, ${ }^{29}$ and appears comparable in efficacy with hydroxychloroquine..$^{30}$ The optimum dose appears to be $6 \mathrm{mg}$ daily, best given in two divided doses of $3 \mathrm{mg} .{ }^{31}{ }^{32}$ One interesting finding is that Auranofin will suppress adjuvant arthritis in rats-in contrast with other second line agents, including intramuscular gold ${ }^{33}$ - suggesting that it may essentially be a non-steroidal anti-inflammatory agent. Its diminished potency and fewer side effects compared with intramuscular gold may be due to the fact that only $15-25 \%$ is absorbed. ${ }^{34}$ Little experience with Auranofin has been reported in diseases other than rheumatoid arthritis, but it may be helpful for patients with psoriatic arthritis ${ }^{35}$-as may intramuscular gold ${ }^{36}$ - with no greater risk than in rheumatoid arthritis of toxic skin reactions. ${ }^{37}$

V WRIGHT

Professor of Rheumatology,

University of Leeds,

Leeds LS2 9PJ
1 Forestier HJ. Rheumatoid arthritis and its treatment by gold salts. 3 Lab Clin Med 1935;20: 827-9. Lande K. Die gunsti

Hartfall SJ, Garland HE, Goldie W. Gold treatment of arthritis; a review of 900 cases. Lancet 1937;ii:784-8.

4 Hartfall SJ, Garland HE, Goldie W. Gold treatment of arthritis; a review of 900 cases. Lancet 1937; ii:838-42.

The Cooperating Clinics Committee of the American Rheumatism Association. A controlled trial of gold salt therapy in rheumatoid arthritis. Arthritis Rheum 1973;16:353-8.

6 Empire Rheumatism Council. Gold therapy in rheumatoid arthritis: report of a multi-centre controlled trial. Ann Rheum Dis 1960;20:315-54.

Sigler JW, Bluhm GB, Suncan H, Sharp JT, McCrum WR. Gold salt in the treatment of rheumatoid arthritis. A double-blind study. Ann Intern Med 1974;80:21-6.

Jickup ME, Bird HA, Lee MR, Wright V, Downie WW. Biochemical indices of response to hydroxychloroquine and sodium aurothiomalate in rheumatoid arthritis. Ann Rheum Dis 1981;40:480-8.

Dequeker J, Van de Venne H, eds.
Rheumatology 1984;3(suppl 1):1-111.

10 Lovgren O, Olhagen V, eds. Proceedings of a symposium: gold in rheumatoid arthritis: the past, present and future. Scand $\mathcal{I}$ Rheumatol 1983 ;suppl 51

11 Blodgett RC, Heuer MA, Pietrusko RG. Auranofin: a unique oral chrysotherapeutic agent. Sem Arthritis Rheum 1984;13:255-73.

12 McConkey B, Crockson RA, Crockson AP. The assessment of rheumatoid arthritis. A study based on measurement of serum acute-phase reactants. $Q \mathcal{F}$ Med 1972;41:115-25.

3 Luukkianen R. Chrysotherapy in rheumatoid arthritis with particular emphasis on the effect of chrysotherapy on radiographic changes and on the optimal time of initiation of therapy. Scand 7 Rheumatol 1980 ; suppl 34.

4 Adams KL, Cecil RL. Gold therapy in early rheumatoid arthritis. Ann Intern Med 1950;33:63. Kenzie JMM. Report on a double-blind trial comparing small and large doses of gold in the treatment of rheumatoid disease. Rheumatol Rehabil 1981;20:198-202.

Freyberg RH, Ziff M, Baum K. Gold therapy for rheumatoid arthritis. In: Hollander JL, 445-64.

17 Rothermich NO, Philips VK, Bergen W, Thomas MH. Chrysotherapy. A prospective study. Arthritis Rheum 1976;19:1321.

8 Griffin AJ, Gibson T, Huston G, Taylor A. Maintenance chrysotherapy in rheumatoid arthritis: a comparison of 2 dose schedules. Ann Rheum Dis 1981;40:250

9 Jellum E, Aaseth J, Munthe E. Is the mechanism of action during treatment of rheumatoid arthritis with penicillamine and gold thiomalate the same? Proceedings of the Royal Society of Medicine 1977,70(suppl 3):136-9.

20 Lyle WH, Kleinman RL, eds. Penicillamine at 21: its place in therapeutics now. Proceedings of the Royal Society of Medicine 1977;70(suppl 3):1-146.

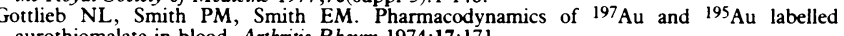
aurothiomalate in blood. Arthritis Rheum 1974;17:171. Sharp JT, Lidsky MD, Duffy J, et al. Comparison of two dosage schedules of gold salts in the
treatment of rheumatoid arthritis. Arthritis Rheum 1971;20:1179.

23 Glennas A. Gold resistance in cultured human cells, possible role of metallothionein. Scand $\mathcal{f}$ Rheumatol 1983;suppl 51:42-4.

24 Panayi GS, Woolley P, Batchelor JR. Genetic basis of rheumatoid disease: HLA antigens, disease manifestations, and toxic reaction to drugs. $\mathrm{Br}$ Med $\mathcal{~ J ~ 1 9 7 8 ; i i : ~ 1 3 2 6 - 8 . ~}$

Husby G, Gran JT. Risk factors in the treatment of rheumatoid arthritis with parenteral gold. Scand f R Reumatol 1983;suppl 51:112-5.

$6 \mathrm{Katz}$ WA, Alexander S, Balnd JH, et al. The efficacy and safety of Auranofin compared to placebo in rheumatoid arthritis. $\mathcal{J}$ Rheumatol 1982;9(suppl 8):173-8.

27 Ward JR, Williams HJ, Egger MJ, et al. Comparison of Auranofin, gold sodium thiomalate, and placebo in the treatment of rheumatoid arthritis: a controlled clinical trial. Arthritis Rheum

8 Girdwood RH. Death after taking medicaments. Br Med 7 1974;i:501-4.

Lewis D, Capell HA. Oral gold; a comparison with placebo and intramuscular sodium aurothiomalate. Clinical Rheumatology 1984;3(suppl 1):83-95.

Bird HA, Le Gallez P, Dixon JS, et al. A single-blind comparative study of Auranofin and 1):57-66

1 Bernhard GC. Auranofin treatment for adult rheumatoid arthritis. Comparison of $2 \mathrm{mg}$ and $6 \mathrm{mg}$ daily dose. I R heumatol 1982;9(suppl 8):149-53.

Calin A, Saunders D, Bennett R, et al. Auranofin: $1 \mathrm{mg}$ or $9 \mathrm{mg}$ ? The search for the appropriate dose. I Rheumatol 1982;9(suppl 8):146-8.

3 Dimartino MJ, Walz DT. Inhibition of lysosmal enzyme release from rat leucocytes by Auranofin, a new crysotherapeutic agent. Inflammation 1977;2:131-42.

Furst DE, Dromgewole SH. Comparative pharmacokinetics of triethylphosphine gold (Auranofin), and gold sodium thiomalate (GST). Clinical Rheumatology 1984;3(suppl 1):17-24. Dequeker J, Verdickte W, Gevers G, Vanschoubroek K. Long term experience with oral gold in rheumatoid arthritis and psoriatic arthritis. Clinical Rheumatology 1984;3(suppl 1):67-73. efficacy and toxicity compared to rheumatoid arthritis. Arthritis Rheum 1978;21:513-5. Wright V. Psoriatic arthritis: a comparative study of rheumatoid arthritis and arthritis associated with psoriasis. Ann Rheum Dis 1961;20:123-32.

\section{The third drug in hypertension}

Evidence suggests that prolonged control of raised blood pressure will prevent the complications of stroke and renal impairment, and to a less extent myocardial infarction. ${ }^{1.3}$ The choice of a first line drug in patients with mild to moderate hypertension usually lies between a $\beta$ adrenoceptor blocking drug and a thiazide diuretic. Opinion is, however, turning against the prolonged use of thiazide diuretics, at least in the high doses currently used. ${ }^{4}$ If neither of these agents alone controls pressure satisfactorily the conventional practice is to give them together, either as separate tablets or in a combined preparation. But what should the doctor do if treatment with diuretics and $\beta$ blockers together fails to control the blood pressure? Should he wipe the therapeutic slate clean and start again, or is there a place for adding a third drug to the regimen? Here the increased risk of poor patient compliance with complicated drug regimens 
(especially in the elderly) has to be balanced against an expectation of the benefits of improved control.

The stratagem of progressively ordered addition of hypotensive drugs to control blood pressure is known as "step care." Diuretics and $\beta$ blockers (or $\beta$ blockers and diuretics) are widely accepted as the first two steps, but there is little consensus on the third, although an arteriolar vasodilator is often given. Several years ago, Koch-Weser and his colleagues put forward a convincing argument for the combination of a vasodilator, a $\beta$ blocker, and a diuretic. ${ }^{5}$ They suggested that, while lowering peripheral vascular resistance and hence blood pressure, administration of a vasodilator leads to a reflex increase in the activity of the renin-angiotensin-aldosterone axis and of the sympathetic nervous system. This results in fluid retention-which tends to negate the fall in pressure (hence the use of a diuretic) - and in an increase in the heart rate (hence the use of a $\beta$ blocker).

If we accept the case for a vasodilator as the third step, which vasodilator should we use? In a recent study from Glasgow and Sheffield of 238 patients whose blood pressure was not controlled with bendrofluazide $5 \mathrm{mg}$ a day and atenolol $100 \mathrm{mg}$ a day, hydralazine, minoxidil, and prazosin (vasodilators), methyldopa (which acts centrally), and the combined $\alpha$ and $\beta$ blocking agent labetalol were compared. ${ }^{6}$ Reassuringly, all third line active drugs were more effective than placebo. Minoxidil was more effective than the others, whose potency was similar. Potency, however, is not the only consideration in the risk versus benefit argument on antihypertensive treatment, and adverse effects and patient acceptability are equally important. When these aspects were taken into account hydralazine emerged as the best third line drug, with prazosin a close second. Minoxidil was effective in patients with less severe hypertension. Methyldopa was less acceptable than either prazosin or hydralazine.

The paper states that all treatment regimens were agreed with the pharmaceutical companies who supplied the drug. The regimen for labetalol (which has $\beta$ blocking activity) entailed the withdrawal of atenolol immediately before labetalol administration in a starting dose of $400 \mathrm{mg}$ twice daily. The incidence of adverse effects with this regimen was high, and in terms of acceptability, labetalol came bottom of the list. This advice on dosage from the manufacturers of labetalol is surprising, because evidence suggests that the drug is both effective and well tolerated if the dose is built up progressively from 150 or $200 \mathrm{mg}$ a day. ${ }^{78}$

Hydralazine has long occupied an equivocal position in the treatment of hypertension in Britain. Its effectiveness has not been questioned (especially in a step care programme), but the incidence of adverse effects, especially drug induced lupus, has given rise to concern. ${ }^{9}$ Cameron and Ramsay have reassessed this problem in a recent study of 281 patients who had been taking hydralazine for about 51 months. ${ }^{10}$ After three years' treatment the incidence of lupus was almost $7 \%$, $\frac{\text { W }}{3}$ and they confirmed that the phenomenon was dose dependent: no cases were recorded in patients taking $50 \mathrm{mg} \stackrel{2}{\mathrm{C}}$ hydralazine a day, but the incidence in patients taking $100 \widehat{\widehat{\Omega}}$ $\mathrm{mg}$ a day was $5.4 \%$ and it was doubled to $10.4 \%$ in those on $\overline{\overline{5}}$ $200 \mathrm{mg}$ a day. (The doses of hydralazine used in the Glasgow ${ }_{0}$ and Sheffield study cited earlier ranged from 25 to $200 \mathrm{mg}$ a day, but the study lasted only six months, which is probably $\stackrel{0}{0}$ too short to see the development of drug induced lupus.) The incidence of lupus was higher in women (12\%) than men $\stackrel{\text { s. }}{+}$ (3\%); in women taking $200 \mathrm{mg}$ hydralazine a day the three year incidence was $19 \%$. Knowledge of the patient's acetylator $\frac{}{\overline{0}}$.

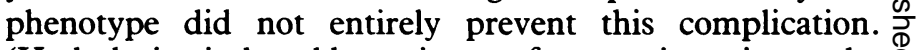
(Hydralazine induced lupus is most frequent in patients who $\stackrel{\circ}{\circ}$ are slow acetylators of the drug; paradoxically, these are the क patients who respond best to it.) The authors conclude $\vec{\circ}$ that the incidence of hydralazine induced lupus is unaccept- $\overrightarrow{\vec{\omega}}$ ably high when it is prescribed according to current $\stackrel{\sim}{\sim}$ recommendations.

The findings of these two important studies make the choice of a third line drug in hypertension difficult, and with ${ }_{0}^{\circ}$ the introduction of two other groups of agents the philosophy 8 of triple therapy needs to be reassessed. Angiotensin convert- $\frac{\vec{t}}{\hat{0}}$ ing enzyme inhibitors show therapeutic potential in all grades of of hypertension, especially when combined with diuretics 0

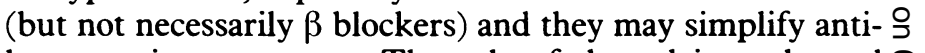
hypertensive treatment. The role of the calcium channel $\sigma$ blocking drugs, as first, second, or third line drugs, is less easy to define.

Perhaps the best indication of the way that antihyperten- $\stackrel{\mathbb{\Phi}}{\frac{}{\circ}}$ sive treatment will move in the next few years will come from $\vec{\bullet}$ studies of the effectiveness of hypotensive drugs in the $\stackrel{\infty}{\oplus}$ primary prevention of ischaemic heart disease. Combinations 0 of hypotensive agents will, no doubt, continue to be used, 方 but the constituents of the therapeutic cocktail of the future are uncertain.

Professor of Clinical Pharmacology,

ALASDAIR BRECKENRIDGE $\stackrel{\circ}{\stackrel{\circ}{\circ}}$

University of Liverpool,

Liverpool L69 3BX

Breckenridge A, Dollery CT, Parry EHO. Prognosis of treated hypertension. Q 7 Med 1970;39: 411-23.

Veterans Administration Comparative Study on Antihypertensive Agents. Effects of treatment on morbidity in hypertension. FAMA 1967;202:1028-34.

Management Committee. The Australian therapeutic trial in mild hypertension. Lancet 1980; $1261-7$.

Ames RP. Negative effects of diuretic drugs on metabolic risk factors for coronary heart disease. Am f Cardiol 1983;51:632-8.

Zacest R, Gilmore E, Koch-Weser J. Treatment of essential hypertension with combined vasodilation and beta adrenergic blockade. $N$ Engl $\mathcal{F}$ Med 1972;286:617-21.

6 McAreavey D, Ramsay LE, Latham L, et al. Third drug trial; comparative study of antihypertensive agents added to treatment when blood pressure remains uncontrolled by a beta blocker plus $\mathrm{O}$ thiazide diuretic. Br Med f 1984;288: 106-11.

Takeda $\mathrm{T}$, Kaneko Y, Omae T, et al. The use of labetalol in Japan; results of multicentre clinical $N$

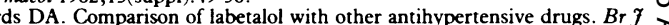

Clin Pharmacol 1982;13(suppl 1):41-7.
Bing RF, Russell GI, Thurston H, Swales JD. Hydralazine in hypertension: is there a safe dose? BrMed F 1980;281:353-4.

10 Cameron HA, Ramsay LE. The lupus syndrome induced by hydralazine: a common complication with !ow dose treatment. Br Med $\mathcal{F} 1984 ; 289: 410-2$. 